\title{
Dwarfism with gloomy face: a new syndrome with features of $3-M$ syndrome
}

\author{
M Le Merrer, R Brauner, P Maroteaux
}

\begin{abstract}
Nine children with primordial dwarfism are described and a new syndrome is delineated. The significant features of this syndrome include facial dysmorphism with gloomy face and very short stature, but no radiological abnormality or hormone deficiency. Mental development is normal. The mode of inheritance seems to be autosomal recessive because of consanguinity in three of the four sibships. Some overlap with the 3-M syndrome is discussed but the autonomy of the gloomy face syndrome seems to be real.
\end{abstract}

The classification of primary dwarfism is based on certain facial features and body dysmorphism. We have observed a new form of dwarfism associated with intrauterine growth retardation and particuliar dysmorphism without chondrodysplasia or hormone deficiency. Four sibships are described and in three cases the parents are cousins, so autosomal recessive inheritance is likely. We propose that this new syndrome be called dwarfism with gloomy face, because this seems to be the main feature.

Case reports (fig 1)

FAMILY 1 (FIG 2)

Case 1 was born after an uncomplicated pregnancy. Birth weight was $2700 \mathrm{~g}$, height $42 \mathrm{~cm}$, and head circumference $37 \mathrm{~cm}$. She was small from birth

U12 Unité de Recherche INSERM sur les Handicaps Génétiques de l'Enfant, Hôpital des Enfants-Malades, 149 rue de Sèvres, 75743 Paris Cedex 15, France.

$M$ Le Merrer

Service d'Endocrinologie Pédiatrique, Hôpital des Enfants-Malades, Paris, France.

R Brauner

URA 584 CNRS, Hôpital des Enfants-Malades, Paris, France.

P Maroteaux

Correspondence to Dr Le Merrer.

Received for publication 23 March 1990.

Revised version accepted for publication 20 July 1990. onwards. She was first seen when she was 5 years 9 months. Height and weight were more than 3.5 SD below the mean (height $94.5 \mathrm{~cm}$, weight $13.6 \mathrm{~kg}$ ) but the head circumference was about +1.5 SD. The face was round with full cheeks. The skull was dolichocephalic, with a high and broad forehead. The eyebrows were horizontal and the palpebral fissures were downward slanting. The nasal bridge was flat and the nose short and bulbous with anteverted nares. The philtrum was long and the mouth open with thick lips. The trunk seemed to be short, but the abdomen was large and hypotonic. There was laxity of the joints and a dimple in the clavicular region. The hands and feet were small but proportionate. $X$ ray of the skeleton showed no abnormality, the vertebral bodies were normal, and bone age was concordant with chronological age. A skull $x$ ray showed a normal sella turcica and dolichocephaly.

This girl had normal mental development, motor milestones were a little delayed, but language was well developed. No hypoglycaemic episode was notified. Endocrine evaluation was normal: T3 $45 \mathrm{pg} / \mathrm{ml}$, T4 $10.5 \mathrm{pg} / \mathrm{ml}$, TSH $1.3 \mu \mathrm{U} / \mathrm{ml}$. Growth hormone peak after arginine-insulin stimulation was $37 \mathrm{mg} / \mathrm{ml}$.
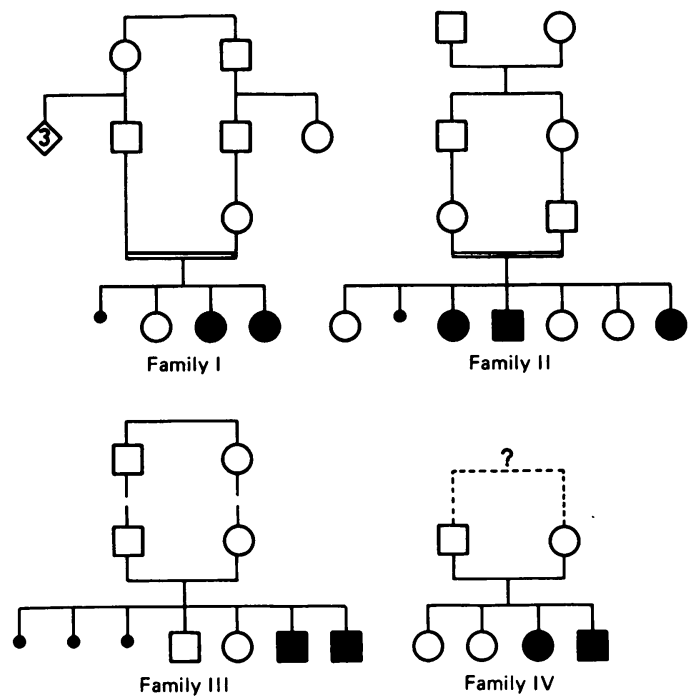

Figure 1 Family pedigrees. 
Case 2 was the younger sister. She was born at 40 weeks of gestation after a normal pregnancy. Birth weight was $2700 \mathrm{~g}$ ( $-2 \mathrm{SD}$ ), height $43.5 \mathrm{~cm}$ (3 SD), and head circumference $36.5 \mathrm{~cm}$ (95th centile).

When she was 2 years 9 months, height was more than $3.5 \mathrm{SD}$ below the mean $(80.5 \mathrm{~cm})$ and weight was $11.05 \mathrm{~kg}$. Head circumference was $50 \mathrm{~cm}$ (+1 SD).

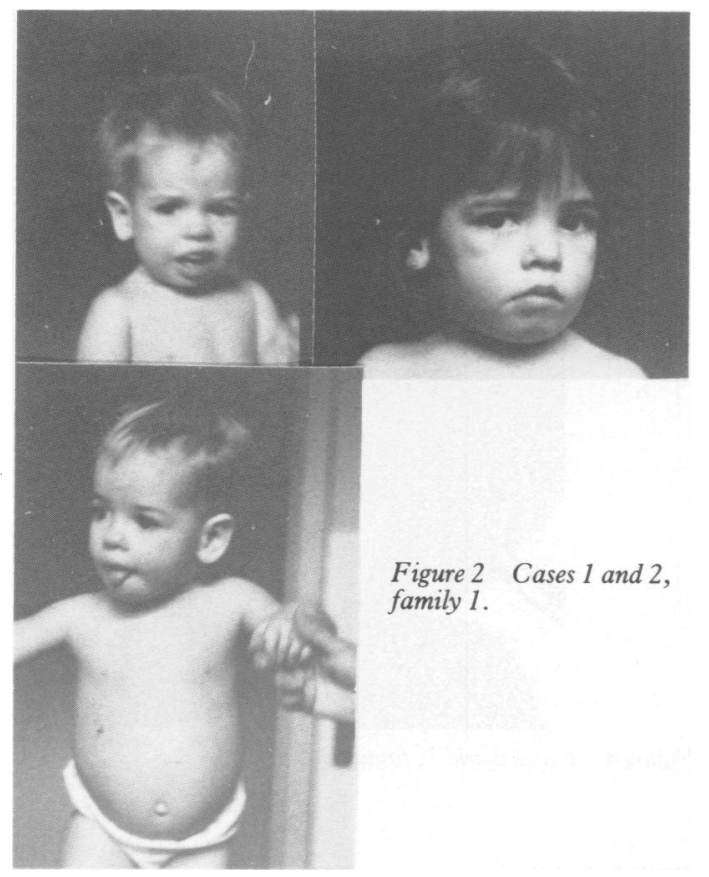

The dysmorphism was even more pronounced than in her older sister: the face was similar with a short nose, anteverted nares, and full lips. She had short stature with a hypotonic abdominal wall. Radiological examination was normal and the bone age was 1.5 years at a chronological age of 2 years. Laboratory tests were also normal: serum electrolytes, creatinine, growth hormone peak after arginine-insulin 19.8 $\mathrm{ng} / \mathrm{ml}$, serum iron $22 \mathrm{~mol} / \mathrm{l}$.

Their parents were healthy but a miscarriage before the birth of both girls was notified. There was consanguinity as the parents were second cousins.

\section{FAMILY 2 (FIG 3)}

This family was from the Maghreb and the parents were first cousins and healthy. Their first child died on the second day without malformation. After that, a miscarriage was notified.

Case 3 was seen when she was 1 year old. Her birth weight was $2230 \mathrm{~g}(-3.5 \mathrm{SD})$, height $40 \mathrm{~cm}(<4.5$ SD), and head circumference $35 \mathrm{~cm}(+1.5 \mathrm{SD})$. She was a hypotonic child with a round face, macrocephaly, large forehead, a depressed nasal bridge, short nose, and full lips. The trunk was short, and there was a laxity of the joints without dislocation. $X$ rays showed no abnormality of the skeleton. Systematic urography was performed and showed horseshoe kidney. The karyotype was normal $(46, X X)$. No hypoglycaemic attack was noted.

When she was 10 , her height was $109.5 \mathrm{~cm}(-4 \mathrm{SD})$ and head circumference $53 \mathrm{~cm}$. Growth was slow but regular. The dysmorphic features were similar: the face was gloomy and round, the forehead high and large with a short and bulbous nose.

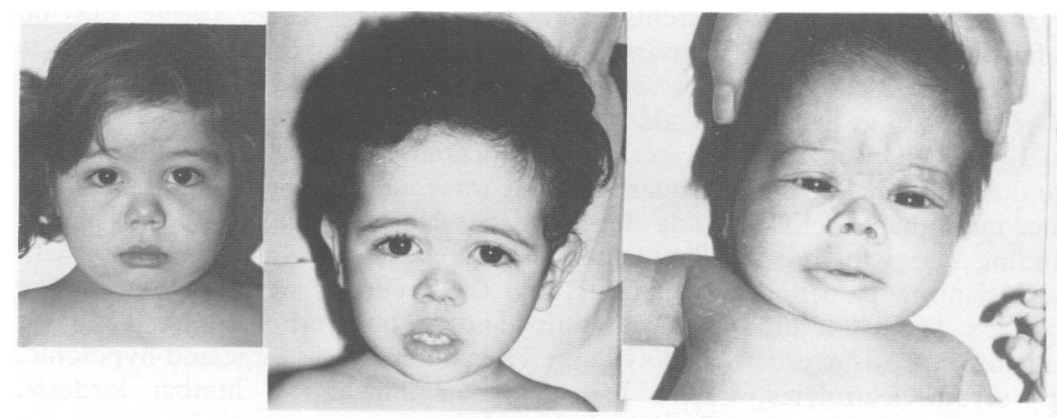

Figure 3 Cases 3, 4, and 5, family 2.

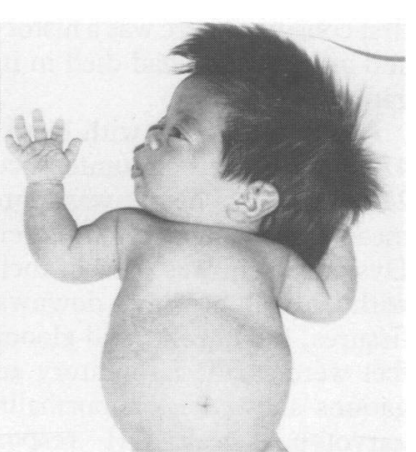


Endocrinological evaluation was normal: growth hormone peak after arginine-insulin stimulation was $17 \cdot 2 \mathrm{ng} / \mathrm{ml}$, TSH $2 \cdot 84 \mu \mathrm{U} / \mathrm{ml}, \mathrm{T} 424 \mathrm{pg} / \mathrm{ml}$. Prolactin, FSH, and LH were normal. Somatomedin C insulinlike growth factor I $\left.\left(I^{\prime G F}\right)_{1}\right)$ was normal $(1 \cdot 34 \mu \mathrm{U} / \mathrm{ml})$.

Case 4, the third child, was born after a normal, term pregnancy. Birth weight was $2300 \mathrm{~g}(-2.5 \mathrm{SD})$, height $44 \mathrm{~cm}(<-3.5 \mathrm{SD})$, and head circumference $34 \mathrm{~cm}$.

At birth there were similar dysmorphic features to her sister's. Micromelia with a short trunk and large abdomen was noted without other physical abnormality. The neurological examination was normal. $X$ rays of the trunk and limbs did not show any abnormality. Urography showed a duplex urinary system. T4 and TSH were normal. Growth seemed to be regular but very slow.

Case 5 was the last child of this family. Birth weight was $2200 \mathrm{~g}$, height $40 \mathrm{~cm}$, and head circumference 34 $\mathrm{cm}$. The face was round with a very depressed nasal bridge, the eyebrows were horizontal, and the philtrum was long. The upper lip was protuberant and full. The hands were square with marked folds. This child was hypotonic with a protuberant abdomen.

Radiological examination and urinary echography were normal. The long bones were not slender. When she was 1 year 7 months, her bone age was 1 year. She had short stature $(<-4$ SD) and endocrine evaluation was performed: prolactin, $\mathrm{T} 4$, and TSH were normal. Growth hormone peak after arginine was $10 \mathrm{ng} / \mathrm{ml}$.

\section{FAMILY 3 (FIG 4)}

In this sibship of four children, two of them had dwarfism. As in the other families, the parents were first cousins. There was a history of three miscarriages, and an older boy had died in infancy without investigation.

Case 6 was a boy with birth weight $3450 \mathrm{~g}$, height $47 \mathrm{~cm}$, and head circumference $39 \mathrm{~cm}$. When he was 27 months, his height was more than 4 SD below the mean and the head circumference more than +1 SD. Dysmorphism was present including a large forehead with frontal bossing, downward slanting palpebral fissures, full cheeks, and gloomy face. The hands and feet were small. Laboratory and radiological investigations showed no abnormality: serum electrolytes, karyotype, peak GH response $(18.7 \mathrm{ng} / \mathrm{ml})$ to arginine-insulin stimulation, and TSH and T4 levels were normal. Bone age was 1 year 3 months at a chronological age of 3 years. The vertebral lumbar bodies and the long bones were normal.

Like his brother, case 7, the second boy, was small at birth (height $43 \mathrm{~cm}$, weight $3080 \mathrm{~g}$, and head circumference $37 \mathrm{~cm}$ ). The face was characteristic. The neck was short with a low posterior hairline. All laboratory tests were normal.

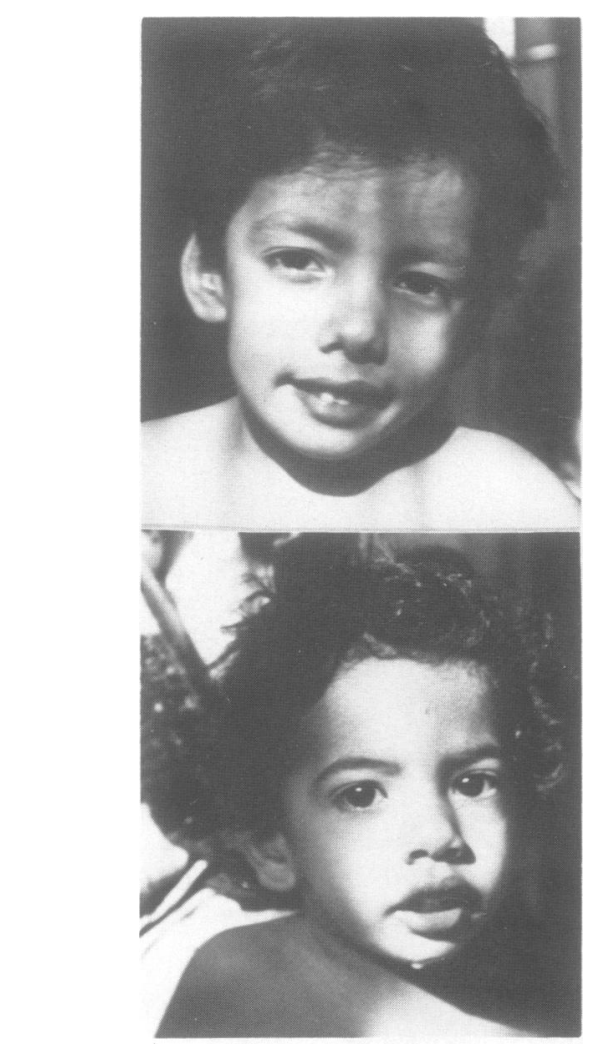

Figure 4 Cases 6 and 7, family 3.

FAMILY 4 (FIG 5)

This family of four sibs was from the Maghreb. The parents were born in the same village but no consanguinity was known. The third girl, case 8 , was short at birth (weight $3020 \mathrm{~g}$, height $43 \mathrm{~cm}$ ) with small hands like her younger brother, case 9 (height $48 \mathrm{~cm}$ ). The appearance of these two children was similar. The face was round with a small nose, flat and wide depressed nasal bridge, and anteverted nares. The palpebral fissures were downward slanting with epicanthus, and the eyebrows were horizontal. The lips were pulpy and the philtrum was long. They had a sulky look. The abdomen was large and hypotonic. Both had genu valgum and a lumbar lordosis. Radiological examination was normal, except for short metacarpals. No laboratory investigations were performed.

\section{Discussion}

These nine children seem to have a new form of primary dwarfism. The main features are dwarfism at birth (remaining below the 5th centile), scaphocephaly with a large forehead, a distinctive, round, 
gloomy face with full lips, horizontal eyebrows, short nose, and anteverted nostrils. The abdomen is large and hypotonic and the thorax is short. Representative radiographs are shown in figs 6 to 8. No radiological abnormality could be found and all the hormonal data

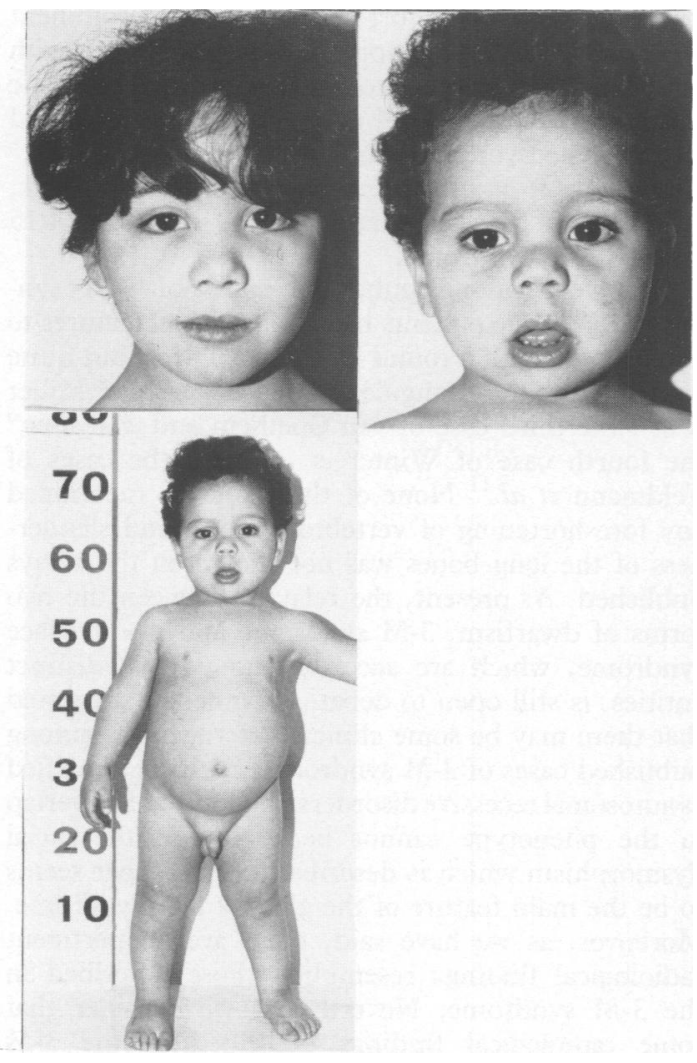

Figure 5 Cases 8 and 9, family 4. were normal including GH level, blood glucose, somatomedin $\mathrm{C}$, and luteinising hormonal thyroid function. Therefore, a hormonal aetiology can be excluded, as well as malabsorption and renal dysfunction. The bone age is not delayed and the mental development of these children is normal. It is probable that the mode of inheritance is autosomal recessive. Three of the four families are consanguineous and the parents in the fourth came from the same village. The syndrome is distinct from other primary forms of dwarfism. Hallermann-Streiff
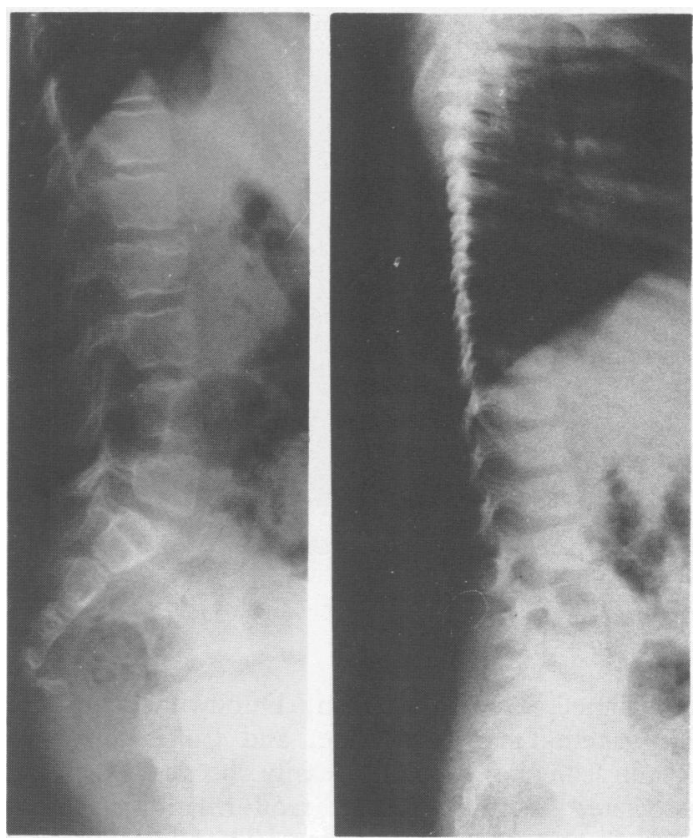

Figure $7 X$ rays of spine of cases 3 and 9. Note lack of foreshortening of vertebral bodies.

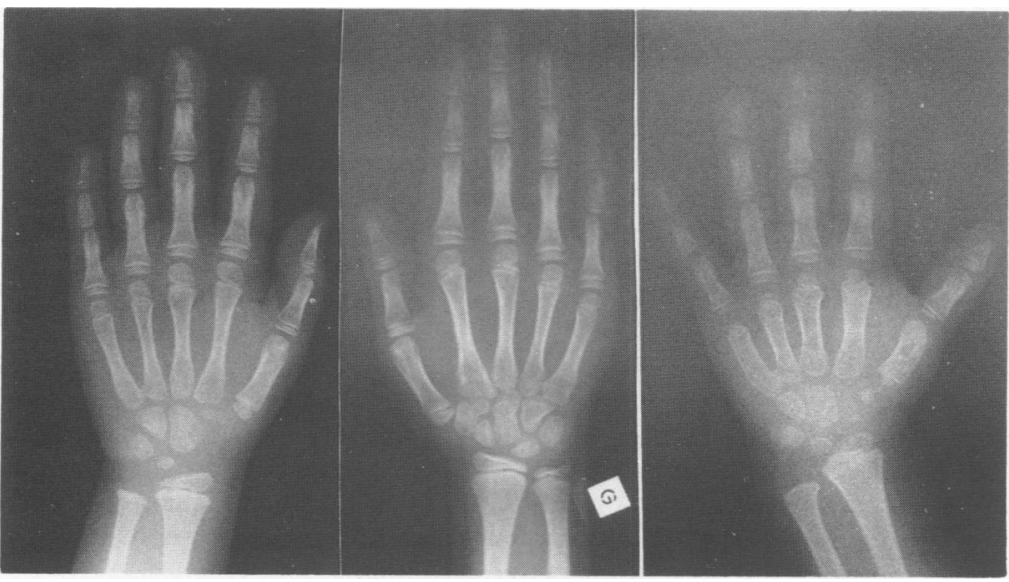

Figure 6 Hand $x$ rays of cases 1,3 , and 9 . 


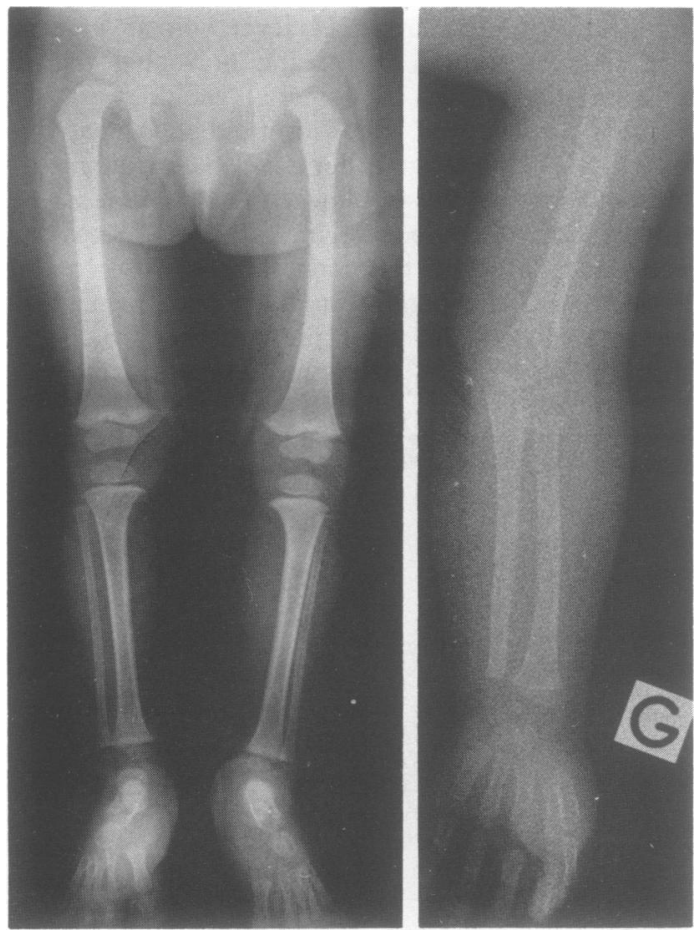

Figure 8 Cases 2 and 9: note absence of slenderness of long bones.

syndrome, Seckel dwarfism, Dubowitz syndrome, Rubinstein-Taybi syndrome, and Coffin-Siris syndrome can be excluded easily because they are associated with different malformations, microcephaly, and mental retardation. ${ }^{1}$ The clinical findings in our nine children differ also from Silver-Russell syndrome: the face is quite different, round in our cases, triangular in Silver-Russell dwarfism. Neither asymmetry nor developmental delay is present. ${ }^{2}$

Some features, such as round facies, dwarfism, and short or snub nose, are common with pituitary dwarfisms. However, our patients have never had growth hormone abnormality, even after arginineinsulin stimulation, nor do they have low somatomedin C, hypoglycaemia, or other features which can indicate pituitary dwarfism or pseudopituitary dwarfism, such as Laron disease.

However, Black ${ }^{3}$ in a review of low birth weight dwarfism reported a snub nose syndrome which is close to the description of our patients: some patients were probably hypopituitary dwarfs, others were different because of autosomal dominant disease, but the above case may be the first of our new syndrome. Consanguinity was also present and autosomal recessive inheritance is likely.

In 1975 Miller $e t a l^{4}$ described a type of dwarfism which they distinguished from other syndromes of primary dwarfism by characteristic facial features, without microcephaly and mental retardation: they called it the 3-M syndrome. Spranger et $a l^{5}$ independently observed the same condition. In the initial description by Miller $e t a l^{4}$ the dysmorphism is quite different from that of our patients: the face was triangular without a short nose but with a prominent philtrum. They also emphasised slender bones with thin diaphyses and retarded bone age. Hypoplastic iliac bones, short femoral neck, prominent talus, and foreshortened vertebral bodies have been described. ${ }^{6}$ Hennekam et $a l,{ }^{7}$ in a review of published reports, found tall or foreshortened vertebral bodies in 14/15 cases of 3-M syndrome.

However, among published cases of 3-M syndrome,$^{8-10}$ some patients had similar facial features to our patients with a round face and full lips, but quite distinct from the triangular face of the cases of Miller et $a l^{4}$ : the third case of van Goethem and Malvaux, ${ }^{6}$ the fourth case of Winter et $a l^{8}{ }^{8}$ and the cases of Feldmann $e t$ al. ${ }^{11}$ None of these reports mentioned any foreshortening of vertebral bodies, and slenderness of the long bones was not shown on the $x$ rays published. At present, the relation between the two forms of dwarfism, 3-M syndrome and gloomy face syndrome, which are according to us two distinct intities, is still open to debate. Flannery ${ }^{12}$ suggested that there may be some clinical heterogeneity among published cases of 3-M syndrome. Both are classified as autosomal recessive disorders. Though some overlap in the phenotype cannot be excluded, the facial dysmorphism which is described in this paper seems to be the main feature of the gloomy face syndrome. Moreover, as we have said, there are no pertinent radiological findings resembling those described in the 3-M syndrome. Nevertheless we consider that some radiological findings described in the 3-M syndrome are questionable: on one hand the slenderness of the long bones is not specific to this syndrome and in some other forms of primary dwarfism slender bones may be seen. On the other hand it is possible that the vertebral findings do not allow early recognition because in our experience foreshortening of the vertebral body is only recognised in older children or adults. For these reasons we have classed our observations together with the cases of Fuhrmann et $a^{13}$ which are considered by several authors to be cases of 3-M syndrome.

Finally, we propose that this disorder should be recognised as a separate syndrome and suggest that the gloomy face may be the only specific finding in this autosomal recessive disorder. Genetic counselling should be cautious and the growth prognosis is uncertain but all these children have good mental development. The pathogenesis of this syndrome remains unknown but further descriptions will be useful for better definition. 
We thank Dr J C Ropert, Dr J Chassevent, and Dr Bonnal for their kind collaboration and Roseline Leroy for her secretarial assistance.

1 Lyons Jones K. Smith's recognizable patterns of human mal formation. 4th ed. Philadelphia: Saunders, 1988.

2 Saal HM, Pagon RA. Reevaluation of Russell-Silver syndrome. I Pediatr 1985;107:733-7.

3 Black J. Low birth weight dwarfism. Arch Dis Child 1961;36: 633-44.

4 Miller JD, McKusick VA, Malvaux P, Temtamy S, Salinas C. The 3-M syndrome: a heritable low birthweight dwarfism. Birth Defects 1975;XI(5):39-47.

5 Spranger J, Opitz JM, Nournand A. A new familial intrauterine growth retardation syndrome: the ' $3-M$ syndrome'. Eur $\mathcal{F}$ Pediatr 1976;123:115-24.
6 Van Goethem H, Malvaux P. The 3-M syndrome: a heritable low birthweight dwarfism. Helv Paediatr Acta 1987;42:159-65.

7 Hennekam RCM, Bijlsma JB, Spranger J. Further delineation of the 3-M syndrome with review of the literature. Am $\mathcal{J}$ Med Genet 1987;28:195-209.

8 Winter RM, Baraitser M, Grant DB, Preece MA, Hall CM. The 3-M syndrome. F Med Genet 1984;21:124-8.

9 Cantu JM, Garcia-Cruz D, Sanchez-Corona J, Fragoso R, Hernandez A, Nazara-Cazorla Z. 3-M slender-boned nanism: an intrauterine growth retardation syndrome. Am $\mathcal{f}$ Dis Child 1981;135:905-8.

10 Garcia-Cruz D, Cantu JM. Heterozygous expression in 3-M slender boned nanism. Hum Genet 1979;52:221-6.

11 Feldmann M, Gilgenkrantz S, Parizot S, Zarini G, Marchal C. $3 M$ dwarfism: a study of two further sibs. $\mathcal{F}$ Med Genet 1989;26:583-5.

12 Flannery DB. 3-M syndrome. Am f Med Genet 1989;32:252.

13 Fuhrmann W, Ngele E, Gugler R, Adeli E. Familäre minderwuchs mit unproportionert hohen wirbeln. Humangenetik 1972; 16:271-82. 